\title{
Cognitive Factors Related to Drug Abuse Among a Sample of Iranian Male Medical College Students
}

\author{
Farzad Jalilian ${ }^{1}$, Mari Ataee ${ }^{1}$, Behzad Karami Matin¹, Mohammad Ahmadpanah ${ }^{2}$, Touraj Ahmadi Jouybari ${ }^{1}$, \\ Ahmad Ali Eslami ${ }^{3}$, Mohammad Mahboubi ${ }^{4,5}$ \& Mehdi Mirzaei Alavijeh ${ }^{6}$ \\ ${ }^{1}$ Substance Abuse Prevention Research Center, Kermanshah University of Medical Sciences, Kermanshah, Iran \\ ${ }^{2}$ Research Center for Behavioral Disorders and Substances Abuse, Hamadan University of Medical Sciences, \\ Hamadan, Iran \\ ${ }^{3}$ Department of Health Education and Promotion, School of Health, Isfahan University of Medical Sciences, \\ Isfahan, Iran \\ ${ }^{4}$ Abadan School of Medical Sciences, Abadan, Iran \\ ${ }^{5}$ Kermanshah University of Medical Sciences, Kermanshah, Iran \\ ${ }^{6}$ Social Determinants of Health Research Center, Yasuj University of Medical Sciences, Yasuj, Iran \\ Correspondence: Ahmad Ali Eslami, Ph.D of Health Education, Department of Health Education and Promotion, \\ School of Health, Isfahan University of Medical Sciences, Isfahan, Iran. E-mail: eslamiaa@gmail.com
}

Received: December 8, $2014 \quad$ Accepted: January 12, $2015 \quad$ Online Published: February 24,2015
doi:10.5539/gjhs.v7n5p143

\begin{abstract}
Backgrounds: Drug abuse is one of the most serious social problems in many countries. College students, particularly at their first year of education, are considered as one of the at risk groups for drug abuse. The present study aimed to determine cognitive factors related to drug abuse among a sample of Iranian male medical college students based on the social cognitive theory (SCT).

Method: This cross-sectional study was carried out on 425 Iranian male medical college students who were randomly selected to participate voluntarily in the study. The participants filled out a self-administered questionnaire. Data were analyzed by the SPSS software (ver. 21.0) using bivariate correlations, logistic and linear regression at $95 \%$ significant level.
\end{abstract}

Results: Attitude, outcome expectation, outcome expectancies, subjective norms, and self-control were cognitive factors that accounted for $49 \%$ of the variation in the outcome measure of the intention to abuse drugs. Logistic regression showed that attitude $(\mathrm{OR}=1.062)$, outcome expectancies $(\mathrm{OR}=1.115)$, and subjective norms $(\mathrm{OR}=1.269)$ were the most influential predictors for drug abuse.

Conclusions: The findings suggest that designing and implementation of educational programs may be useful to increase negative attitude, outcome expectancies, and subjective norms towards drug abuse for college students in order to prevent drug abuse.

Keywords: drug abuse, college, student, cognitive factors, Iran

\section{Introduction}

Drug abuse is considered as one of the main social problems worldwide. It ruins lots of lives and huge national capitals are spent to deal with its detrimental consequences on societies. Plus social problems, drug abuse can lead to medical as well as psychological conditions (Scholte et al., 2008). In addition, According to the statistics by the World Health Organization (WHO) reports, drug abuse is increasing among teens and young adults; Iran is no exception; recent studies show that 500 new young Iranian adults start to abuse drugs use a drug every day and addicted population grows twice in each 10 years (Khayatipur et al., 2011). Among young adults, collage students at their first year of education are considered particularly as an in danger group for drug abuse. This is attributed to some factors such as entering a new phase of life, leaving their family, peer tension, etc. (Abbasighahremanloo et al., 2014; Barati et al., 2012; Rezakhani Moghadam et al., 2013). Furthermore, studies have noted that training is the most effective method to prevent drug abuse (Tavousi et al., 2013). On the other hand, designing and editing effective prevention plans require deep understanding of causes of the phenomenon and related factors (Springer et al., 2004). The most efficient training programs stem from theoretical approaches 
based on behavior change patterns (Tavousi et al., 2013). Among these, a more common pattern and theory to analyze behavior is the social cognitive theory (SCT). Bandura chose to use some concepts of cognitive psychology to combine it with visual learning principles and introduced SCT. Like other behavior psychology theories, SCT is made of several constructs, and this multiplicity makes researchers to choose certain constructs based on the studied behavior (Bandura, 2001).

Considering drug abuse, several studies pointed out to the roles of the constructs of this theory; for example, Gue et al, showed that having positive believes on alcoholic drinks among 10 and 16 year-olds increases the danger of alcoholic drinks abuse at a later time at 21 years of age to 1.2 and 1.7, respectively (Guo et al., 2001). Tucker et al. suggested that having positive attitude to smoking (e.g.: relaxation) increased smoking risk by 1.7 later at 23 years of age (Tucker et al., 2003). Read et al. study on college students attending their first year of education (an average age of 18 years) showed that peer norms had a positive effect on drinking alcoholic drinks among male students (Read et al., 2002). Weintraub Austin and Chen presented similar results about the role of subjective norms in drug abuse (Weintraub Austin, \& Chen, 2003). Many studies, also, mentioned the importance of self-control in risky behaviors; for example, Jackson introduced low self-control as an important factor on drug abuse among the youth (Jackson, 2000). In addition, Sussman et al. showed meaningful relation between smoking, using alcoholic drinks and marijuana with low self-control (Sussman et al., 2001). Furthermore, Adalbjarnardottir and Rafnsson in a long-term study suggested that the lower the self-control level, the higher anti-social behaviors among students would be. They also reported higher risk of drug and alcohol abuse among such students (Adalbjarnardottir \& Rafnsson, 2002).

Substance abuse, as a non-adaptive pattern of using substances, results in frequent occupational, social, and legal problems (Ahmadpanah et al., 2013). In this regards, drug abuse among college students can be followed several complications, such as reduce academic achievement, educational problems, psychological and physical illnesses, and high risk behavior among students (Barati et al., 2012).

Iran is one of many countries in which the prevalence of the substance abuse has been increasing, especially among the adolescents, young and college students (Ahmadi et al., 2001); furthermore, some study in Iran indicated high rate of substance abuse among medical college students (Homa et al., 2009). Recent studies of the Iranian college students reported high prevalence of the drug abuse, for example 33\% (Rezakhani Moghadam et al., 2013), 10\% (Serajzadeh, 2007); additionally, Mohammad Khani reported that 18.8 percent of students mentioned experience of substance abuse for at least once (Rezakhani Moghadam et al., 2013; Serajzadeh, 2007; Mohammadkhani, 2012). In other hand, several studies have shown that male students are in higher risk of experiencing and abusing drugs than female students (Chassin et al., 2002; Hicks et al., 2007; Hussong \& Chassin, 2004; King \& Chassin, 2007; Steinhausen et al., 2008).

Therefore, the main objective of this study was to determine cognitive factors related to drug abuse among a sample of Iranian male medical college students based on the SCT.

\section{Materials and Methods}

\subsection{Participants and Procedure}

This cross-sectional study was conducted on a sample of male students aged 18 to 22 years old with a mean (SD) age of 19.91 (1.19) years in two medical universities in Iran during 2014. The sample size was calculated at 95\% significant level according to the results of the previous study (Rezakhani Moghadam et al., 2013) and considering $20 \%$ attrition rate, a sample of 425 was estimated. Of the population of 425,355 of them signed the consent form and voluntarily agreed to participate in the study. Respond rate the response rate was $84 \%$. The study protocol was approved by the institutional review board of the Isfahan University of Medical Sciences; furthermore our research project was approval by the committee of ethics of the Isfahan University of Medical Sciences, the center of Iran.

\subsection{Measures}

Prior to conducting the main project, a pilot study was conducted to assess the utility of the instrument. The pilot study participants were 18 male medical college students, similar to those who participated in the main study. The pilot study was conducted to obtain feedback about the clarity, length, comprehensiveness, and completion time of the various instruments as well as collecting data to estimate the internal consistency of the measures.

\subsection{Demographics Scale}

Background data gathered included age, marital status (single or married), faculty (medical, dentist, pharmacy, health and nutrition, paramedical, nursing), level of parents' education (primary school, secondary school, high school diploma, and academic education), having friends who had history of drug use (yes, no), having family who had history of drug use (yes, no), parents' divorce (yes, no), living place (with parents, dormitory, others), 
and history of persuasion due to drug use.

\subsection{Drug Use}

To assess whether or not the respondents had current drug use, we used their responses to one question: "have you abused drug during the past three months?" The response was "Yes" or "No".

\subsection{Predictive Variables (Social Cognitive Theory)}

Predictive factors for drug use included some variables of the SCT. This section included 47 items which were composed under six major constructs including (1) attitude towards drug use, (2) outcome expectation towards drug use, (3) outcome expectancies towards drug use, (4) subjective norms toward drug use, (5) behavioral intention toward drug use, and (6) self-control.

Attitude, outcome expectation, outcome expectancies, subjective norms, and behavioral intention towards drug use were designed based on a standard questionnaire related to drug use (McMillan \& Conner, 2003; Yeramaneni, 2010; Allahverdipour et al., 2012). Nine items were designed to measure attitude (e.g., drug use for me is: unpleasant-pleasant). Seven items were designed to measure outcome expectation (e.g., if I use drug, I will keep my mind off problems). Seven items were designed to measure outcome expectancies (e.g., how important is it to you that you can keep your mind off problems when you drug use?). Seven items were designed to measure subjective norms (e.g., if I use drug, my best friends will confirm it). Four items were designed to evaluate behavioral intention (e.g., I intend to use drug during university time).

In order to facilitate the participants' responses to the items, outcome expectation, outcome expectancies, subjective norms, and behavioral intention towards drug use were standardized to a 5-point Likert scale, ranging from 1 (strongly disagree) to 5 (strongly agree). Attitude item was standardized to a 7-point Likert scale, ranging from 1 to 7.

Self-control was measured by the Tangney brief self-control scale (Tangney et al, 2004), and included 13 items, for example: "I am good at resisting temptation". Using the 1 (not at all) to 5 (very much) scale.

The reliability coefficients for the abovementioned constructs were as follows: attitude $(\alpha=0.93)$, outcome expectation $(\alpha=0.90)$, outcome expectancies $(\alpha=0.89)$, subjective norms $(\alpha=.74)$, behavioral intention $(\alpha=0.77)$, and self-control $(\alpha=0.75)$.

\subsection{Statistical Analysis}

The data were analyzed by the SPSS software for windows (ver. 21.0) using correlation as well as linear and logistic regression at $95 \%$ significant level.

\section{Results}

Mean age of the respondents was 19.9 years (range, 18-22 years). The initiation age for drug use was 12. Almost, $4.8 \%(17 / 355)$ participants were married and $95.2 \%$ (338/355) were single. $3.4 \%(12 / 355)$ also reported that their parents were divorced. About $44.5 \%$ of the respondents (158/355) were freshman students and 55.5\% $(197 / 355)$ were sophomore students. About $3.9 \%$ of the respondents (14/355) had history of drug use during the past three months. Furthermore, 12.7\% (45/355) stated that they had received suggestions from others to use drugs. Nearly $23.7 \%(84 / 355)$ and $14.9 \%(53 / 355)$ of the respondents reported that their friends and family were having history of drug use, respectively.

Table 1 shows mean $( \pm \mathrm{SD})$ and bivariate correlations between the behavioral intention to drug use, attitude, outcome expectation, outcome expectancies, subjective norms, and self-control which were all statistically significant at 0.01 .

Table 1. Predictor variables of drug abuse based on bivariate correlation analysis

\begin{tabular}{lllllll}
\hline & Mean (SD) & $\mathbf{X}^{\mathbf{1}}$ & $\mathbf{X}^{\mathbf{2}}$ & $\mathbf{X}^{\mathbf{3}}$ & $\mathbf{X}^{4}$ & $\mathbf{X}^{\mathbf{5}}$ \\
\hline $\mathrm{X}^{1}$. Attitude & $17.73(12.61)$ & 1 & & & & \\
$\mathrm{X}^{2}$. Outcome expectation & $13.21(6.71)$ & 0.582 & 1 & & & \\
$\mathrm{X}^{3}$. Outcome expectancies & $14.61(8.42)$ & 0.539 & 0.555 & 1 & & \\
$\mathrm{X}^{4}$. Subjective norms & $12.62(5.27)$ & 0.441 & 0.353 & 0.331 & 1 & \\
$\mathrm{X}^{5}$. Self-control & $42.34(8.52)$ & -0.310 & -0.316 & -.0222 & -.0427 & 1 \\
$\mathrm{X}^{6}$. Behavioral intention & $6.52(3.79)$ & 0.535 & 0.464 & 0.404 & 0.623 & -.0394 \\
\hline
\end{tabular}


A hierarchical multiple regression analysis was performed to explain the variation in behavioral intention to drug use. As shown in Table 2, collectively, the SCT variables accounted for $49 \%$ of the variation in behavioral intention to abuse drugs among the participant.

Table 2. Predictors of the perceptual variables in drug use behavioral intention

\begin{tabular}{llllll}
\hline Variable & $\boldsymbol{B}$ & SE $\boldsymbol{B}$ & Beta & $\boldsymbol{T}$ & $\boldsymbol{P}$-value \\
\hline Step 1 & & & & & \\
Attitude & 0.064 & 0.015 & 0.213 & 4.157 & 0.000 \\
Outcome expectation & 0.073 & 0.029 & 0.129 & 2.555 & 0.011 \\
Outcome expectancies & 0.025 & 0.022 & 0.056 & 1.158 & 0.248 \\
Subjective norms & 0.306 & 0.033 & 0.425 & 9.398 & 0.000 \\
Self-control & -0.042 & 0.019 & -0.094 & -2.194 & 0.029 \\
Step 2 & & & & & \\
Attitude & 0.069 & 0.015 & 0.230 & 4.678 & 0.000 \\
Outcome expectation & 0.084 & 0.027 & 0.149 & 3.136 & 0.002 \\
Subjective norms & 0.309 & 0.032 & 0.429 & 9.526 & 0.000 \\
Self-control & -0.041 & 0.019 & -0.093 & -2.170 & 0.031 \\
SE=Standard Error & & & & & \\
Final model: Step 2, Adjusted $R$ squared=0.49 and $P<0.001$ & & \\
\hline
\end{tabular}

Finally, a logistic regression (backward stepwise method) building procedure was conducted and finally on $3^{\text {rd }}$ step, the procedure stopped and the best model was selected. Among the constructs, attitude, outcome expectancies and subjective norms were the most influential predictive factors for drug use (Table 3).

Table 3. Logistic regression analysis for variables related to drug use

\begin{tabular}{llllllll}
\hline Variables & B & S.E. & Wald & Odds Ratio & $\begin{array}{l}\mathbf{9 5 \%} \\
\text { Intervals }\end{array}$ \\
& & & & \multicolumn{5}{c}{ Confidence } & P-value \\
\hline Step 1 & & & & & Lower & Upper \\
Attitude & 0.049 & 0.029 & 2.823 & 1.050 & 0.992 & 1.111 & 0.093 \\
Outcome expectation & 0.081 & 0.055 & 2.160 & 1.085 & 0.973 & 1.209 & 0.142 \\
Outcome expectancies & 0.108 & 0.060 & 3.266 & 1.114 & 0.991 & 1.253 & 0.071 \\
Subjective norms & 0.214 & 0.081 & 6.945 & 1.239 & 1.056 & 1.453 & 0.008 \\
Self-control & -0.050 & 0.053 & 0.895 & 0.951 & 0.857 & 1.055 & 0.344 \\
Step 2 & & & & & & & \\
Attitude & 0.045 & 0.029 & 2.467 & 1.046 & 0.989 & 1.106 & 0.116 \\
Outcome expectation & 0.076 & 0.054 & 1.969 & 1.076 & 0.970 & 1.201 & 0.161 \\
Outcome expectancies & 0.112 & 0.060 & 3.407 & 1.118 & 0.993 & 1.259 & 0.065 \\
Subjective norms & 0.236 & 0.079 & 9.026 & 1.266 & 1.086 & 1.477 & 0.003 \\
Step 3 & & & & & & & \\
Attitude & 0.060 & 0.028 & 4.745 & 1.062 & 1.006 & 1.121 & 0.029 \\
Outcome expectancies & 0.109 & 0.056 & 3.754 & 1.115 & 0.999 & 1.245 & 0.053 \\
Subjective norms & 0.238 & 0.077 & 9.474 & 1.269 & 1.090 & 1.476 & 0.002 \\
\hline
\end{tabular}




\section{Discussion}

The results of the study indicated that the positive attitude towards drug abuse, outcome expectancies of drug abuse, and subjective norm encouraging to drug abuse were the three main cognitive factors which were associated with drug abuse among Iranian college students attending medical universities.

Attitude is defined as a person's beliefs about the results of a behavior and his/her evaluation of them (Ajzen, 1991); therefore, different studies investigated the attitude role in drug abuse (Umeh \& Patel, 2004; Ghanizadeh, 2008; Jalilian et al, 2013). The obtained results showed that items such as forgetting problems, improving mental powers and increasing self-esteem received highest average scores among other attitude construct questions. This suggests that drug users had better attitude to positive consequences than negative ones (for example, mental problems). Therefore, it seems that training courses should focus on improving negative attitude on using drug and its negative consequences among students.

Outcome expectancies in the SCT is defined as the values that person places on a given outcomes incentives, and outcomes of change that have functional meaning (Bandura, 2001). Results of the present study showed that items such as being happy, feeling fresh and getting mind away from problems while using drug received highest average score among other constructs of outcome expectancies in using a drug. Callas et al. used the SCT to study factors related to consume alcoholic drinks among high-school students in Vermont, the US and suggested that negative expectancies about alcohol were effective factors on consuming alcohol among teens (Callas et al., 2004). Also, Simon-Morton et al. presented similar results in this field (Simons-Morton et al., 1999). In addition, Lam et al. reported that alcohol consumption was significantly associated with increased positive smoking outcome expectancies (Lam et al., 2014). It is needed to focus on psychic factors, which are interfaces and predicators of behaviors, in comprehensive, sanitary instructive programs (Allahverdipour et al., 2012). In other hand, our findings showed outcome expectation was predict drug abuse behavioral intention, but outcome expectancies was a strong factor for prediction drug use behavior. In this regard Bandura noted that outcome expectancies, occasionally mentioned to as 'if . . . then' statements, are the perceived behavioral and affective consequences of engaging in particular behaviors (Bandura, 2002). Our result confirmed previous research, that positive drug outcome expectancies, was a direct and important predictor of drug use (Alfonso \& Dunn, 2007; Connor et al., 2014; Connor et al., 2011). It seem, high positive outcome expectancies (e.g. "can participate more at parties when drug use, can overcome shyness, can keep mind off problems) were associated with drug use behavior, but outcome expectation were predictor drug abuse behavioral intention.

Subjective norms are agreed and genesis criteria which regulate people behaviors. Subjective norms are essential factors in human group construction as they represent motivation and route, organize social interactions and make others' responses predictable and meaningful. Subjective norms introduce correct action methods and show people the things they should avoid. Subjective norms are considered as predictive factors in behavior achievement intention. This construct can be affected by social pressure, or normative beliefs, where its severity depends on people motivation to comply other's expectations (Ajzen, 1991). Many studies mentioned the effects of subjective norms on forming behaviors related to drug abuse (Jalilian et al, 2014; Leitner et al., 1993; Bashirian et al., 2012; Litchfield \& White, 2006). In this regard, Leitner et al. found that 90 percent of participants introduced peer pursers as the main reason to start using drugs (Leitner et al., 1993). Knowing pursers from social and cultural environment of aim group and protective values, positive attitudes and sanitary behaviors and arguing with teens in plans related to them are some of the benefits to use peer group in trainings (Noori Sistani et al., 2010). Efficiency of pursers is the basis of this theory where sensitive information is shared easier among pursers (DiClemente et al., 2001; Karofsky et al., 2001). Trained purser could share information effectively by getting pursers involved and could be more efficient to other pursers by improving; furthermore, a related study showed that only one out of six teens gets information from those others than their pursers (Akbarzadeh et al., 2008). Along with this, Jalilian et al. made use of peer group training approach to prevent anabolic steroid usage and results showed that finishing training program, there was a meaningful decrease in behavioral intention to use anabolic steroids among intervention athletes (Jalilian et al., 2011). Considering the important role of subjective norms in drug abuse and, also, efficiency of using purser training approaches, it is suggested to plan and administer training courses to prevent drug abuse among teens and youth, especially through making use of purser training approach. The present study, also, showed that items such as persuasive environment to use drug and accepting friend's opinions to avoid drug received higher average scores among other subjective norm items, which represented its importance in planning training programs.

\section{Conclusion}

There are multiple factors to explain or predict the drug abuse among youth people. The present study 
moderately confirmed the applicability of the cognitive factors to explain drug abuse among medical college students in Iran. Our finding could be useful for guiding practitioners and implementers to design and implement effective preventative programs to protect the youth from drug abuse.

\section{Acknowledgements}

This article is a part of the Ph.D. dissertation of health education and health promotion supported by Isfahan University of Medical Sciences. We would like to thank Deputy of Research of Isfahan University of Medical Sciences for financial support.

\section{Conflict of Interest Statement}

Authors declare that there is no conflict of interest.

\section{Funding}

This study was funded by the Deputy of Research of Isfahan University of Medical Sciences.

\section{References}

Abbasighahremanloo, A., Allahverdipour, H., \& Augner, C. (2014). Substance Abuse in Relation to Religiosity and Familial Support in Iranian College Students. Asian Journal of Psychiatry, 9, 41-44. http://dx.doi.org/10.1016/j.ajp.2013.12.015

Adalbjarnardottir, S., \& Rafnsson, F. D. (2002). Adolescent antisocial behavior and substance use: Longitudinal analyses. Addictive behaviors, 27(2), 227-240. http://dx.doi.org/10.1016/S0306-4603(00)00179-9

Ahmadi, J., Benrazavi, L., \& Ghanizadeh, A. (2001). Substance abuse among contemporary Iranian medical students and medical patients. The Journal of nervous and mental disease, 189(12), 860-861. http://dx.doi.org/10.1097/00005053-200112000-00009

Ahmadpanah, M., Mirzaei Alavijeh, M., Allahverdipour, H., Jalilian, F., Afsar, A., Haghighi, M., \& et al. (2013). Effectiveness of coping skills education program to reduce craving beliefs among addicts referred to addiction centers in Hamadan: a randomized controlled trial. Iranian Journal of Public Health, 42(10), 1139-1144.

Allahverdipour, H., Jalilian, F., \& Shaghaghi, A. (2012). Vulnerability and the intention to anabolic steroids use among Iranian gym users: An application of the theory of planned behavior. Substance use \& misuse, 47(3), 309-317. http://dx.doi.org/10.3109/10826084.2011.633296

Ajzen, I. (1991). The Theory of Planned Behaviour. Organisational Behav Hum Decision Proces, 50, 179-211. http://dx.doi.org/10.1016/0749-5978(91)90020-T

Akbarzadeh, M., Zangiabadi, M., Moattari, M., \& Tabatabaei, H. (2008). Comparing the Effect of Teaching Breast Self-Examination by Peers and Health Care Personnel on Students Knowledge and Attitude. Iranian Journal of Medical Education, 8(2), 195-202.

Alfonso, J., \& Dunn, M. E. (2007). Differences in the marijuana expectancies of adolescents in relation to marijuana use. Substance use \& misuse, 42(6), 1009-1025. http://dx.doi.org/10.1080/10826080701212386

Bandura, A. (2001). Social cognitive theory: An agentic perspective. Annual review of psychology, 52(1), 1-26. http://dx.doi.org/10.1146/annurev.psych.52.1.1

Bandura, A. (2002). Growing primacy of human agency in adaptation and change in the electronic era. European Psychologist, 7(1), 2. http://dx.doi.org/10.1027//1016-9040.7.1.2

Barati, M., Allahverdipour, H., \& Jalilian, F. (2012). Prevalence and predictive factors of psychoactive and hallucinogenic substance abuse among college students. Journal of Fundamentals of Mental Health, 13(4), 374-383.

Bashirian, S., Hidarnia, A., Allahverdipour, H., \& Hajizadeh, E. (2012). Application of the theory of planned behavior to predict drug abuse related behaviors among adolescents. Journal of research in health sciences, 12(1), 54-59.

Callas, P. W., Flynn, B. S., \& Worden, J. K. (2004). Potentially modifiable psychosocial factors associated with alcohol use during early adolescence. Addictive behaviors, 29(8), 1503-1515. http://dx.doi.org/10.1016/j.addbeh.2004.02.028

Chassin, L., Pitts, S. C., \& Prost, J. (2002). Binge drinking trajectories from adolescence to emerging adulthood in a high-risk sample: predictors and substance abuse outcomes. Journal of consulting and clinical 
psychology, 70(1), 67. http://dx.doi.org/10.1037/0022-006X.70.1.67

Connor, J. P., Gullo, M. J., Feeney, G. F., Kavanagh, D. J., \& Young, R. M. (2014). The relationship between cannabis outcome expectancies and cannabis refusal self-efficacy in a treatment population. Addiction, 109(1), 111-119. http://dx.doi.org/10.1111/add.12366

Connor, J. P., Gullo, M. J., Feeney, G. F., \& Young, R. M. (2011). Validation of the Cannabis Expectancy Questionnaire (CEQ) in adult cannabis users in treatment. Drug and alcohol dependence, 115(3), 167-174. http://dx.doi.org/10.1016/j.drugalcdep.2010.10.025

DiClemente, R. J., Wingood, G. M., Crosby, R., Cobb, B. K., Harrington, K., \& Davies, S. L. (2001). Parent-adolescent communication and sexual risk behaviors among African American adolescent females. The Journal of pediatrics, 139(3), 407-412. http://dx.doi.org/10.1067/mpd.2001.117075

Ghanizadeh, A. (2008). Knowledge of pharmacists regarding ritalin and ADHD and their attitude towards the use of Ritalin to treat ADHD. International journal of clinical pharmacology and therapeutics, 46(2), 84-88. http://dx.doi.org/10.5414/CPP46084

Guo, J., Hawkins, J. D., Hill, K. G., \& Abbott, R. D. (2001). Childhood and adolescent predictors of alcohol abuse and dependence in young adulthood. Journal of studies on alcohol, 62(6), 754-762.

Hicks, B. M., Blonigen, D. M., Kramer, M. D., Krueger, R. F., Patrick, C. J., Iacono, W. G., \& McGue, M. (2007). Gender differences and developmental change in externalizing disorders from late adolescence to early adulthood: A longitudinal twin study. Journal of abnormal psychology, 116(3), 433. http://dx.doi.org/10.1037/0021-843X.116.3.433

Homa, Z., Kiomars, N., Moosa, K., \& Maryam, S. (2009). Substance use among students of Guilan University of Medical Sciences in Iran in 2005-2006. Acta Medica Iranica, 47(6), 473-478.

Hussong, A. M., \& Chassin, L. (2004). Stress and coping among children of alcoholic parents through the young adult transition. Development and psychopathology, 16(4), 985-1006. http://dx.doi.org/10.1017/S0954579404040106

Jackson, K. M., Sher, K. J., \& Wood, P. K. (2000). Prospective analysis of comorbidity: tobacco and alcohol use disorders. Journal of Abnormal Psychology, 109(4), 679. http://dx.doi.org/10.1037/0021-843X.109.4.679

Jalilian, F., Allahverdipour, H., Moeini, B., \& Moghimbeigi, A. (2011). Effectiveness of anabolic steroid preventative intervention among gym users: Applying theory of planned behavior. Health Prom Perspect, $1(1), 32-40$.

Jalilian, F., Karami-Matin, B., Mirzaei-Alavijeh, M., Ataee, M., Mahboubi, M., Motlagh, F., \& Agha, A. (2013). Prevalence and Factor Related to Ritalin Abuse among Iranian Medical College Student: An Application of Theory of Planned Behavior. Terapevticheskii Arkhiv, 85(4s), 31-36.

Jalilian, F. Mari, A., Mahboubi, M., Motlagh, F., Aghaei, A., Mirzaei Alavijeh, M., \& et al. (2014) Explain of Ecstasy Use among Kermanshah Adolescents, the West of Iran: an Application of the Theory of Planned Behavior. Life Sci J, 11(1s), 82-86.

Karofsky, P. S., Zeng, L., \& Kosorok, M. R. (2001). Relationship between adolescent-parental communication and initiation of first intercourse by adolescents. Journal of adolescent health, 28(1), 41-45. http://dx.doi.org/10.1016/S1054-139X(00)00156-7

Khayatipur, A., Ghorban shirudi, Sh., Khalatbari, J. (2011). Comparing Effectiveness of Combined Cognitive Behavioral Therapy in Community Therapy and Narcotic Anonymus Groups on Tendency to Abuse Drugs. Scientific Medical Journal, 9(6), 633-640.

King, K. M., \& Chassin, L. (2007). A prospective study of the effects of age of initiation of alcohol and drug use on young adult substance dependence. Journal of Studies on Alcohol and Drugs, 68(2), 256.

Lam, C. Y., Businelle, M. S., Cofta-Woerpel, L., McClure, J. B., Cinciripini, P. M., \& Wetter, D. W. (2014). Positive smoking outcome expectancies mediate the relation between alcohol consumption and smoking urge among women during a quit attempt. Psychology of Addictive Behaviors, 28(1), 163. http://dx.doi.org/10.1037/a0034816

Leitner, M., Shapland, J., \& Wiles, P. (1993). Drug usage and drugs prevention: The views and habits of the general public. London, UK: HMSO. 
Litchfield, R. A., \& White, K. M. (2006). Young adults' willingness and intentions to use amphetamines: An application of the theory of reasoned action. E-Journal of Applied Psychology, 2(1), 45-51. http://dx.doi.org/10.7790/ejap.v2i1.34

McMillan, B., \& Conner, M. (2003). Applying an Extended Version of the Theory of Planned Behavior to Illicit Drug Use among Students. Journal of Applied Social Psychology, 33(8), 1662-1683. http://dx.doi.org/10.1111/j.1559-1816.2003.tb01968.x

Mohammadkhani, Sh. (2012). Prevalence of Cigarette Smoking, Alcohol Drinking and illegal Drugs Use among Iranian Adolescents. Journal of Kerman University of Medical Sciences, 19(1), 32-48.

Noori Sistani, M., Merghati Khoi, E., \& Taghdisi, M. H. (2010). Promoting Knowledge, Attitude and Practices (KAP) of the Mothers in their Girls Pubertal Health Based on Peer Education Approach. Journal of Babol University of Medical Sciences, 11(6), 33-39.

Read, J. P., Wood, M. D., Davidoff, O. J., McLacken, J., \& Campbell, J. F. (2002). Making the transition from high school to college: The role of alcohol-related social influence factors in students' drinking. Substance Abuse, 23(1), 53-65. http://dx.doi.org/10.1080/08897070209511474

Sohbatzadeh, R. (2013). Comparison of Substance Abuse and its Causes among Students of Tehran University of Medical Sciences and University of Tehran. J Health Syst Res, 8(7), 1300-1310.

Scholte, R. H., Poelen, E. A., Willemsen, G., Boomsma, D. I., \& Engels, R. C. (2008). Relative risks of adolescent and young adult alcohol use: The role of drinking fathers, mothers, siblings, and friends. Addictive behaviors, 33(1), 1-14. http://dx.doi.org/10.1016/j.addbeh.2007.04.015

Serajzadeh, H. (2007). Drug Abuse and Alcohol Drinking among Students. Refah Ejtemaei, 6(25), 85-110.

Simons-Morton, B., Haynie, D. L., Crump, A. D., Saylor, K. E., Eitel, P., \& Yu, K. (1999). Expectancies and other psychosocial factors associated with alcohol use among early adolescent boys and girls. Addictive behaviors, 24(2), 229-238. http://dx.doi.org/10.1016/S0306-4603(98)00095-1

Springer, J. F., Sale, E., Hermann, J., Sambrano, S., Kasim, R., \& Nistler, M. (2004). Characteristics of effective substance abuse prevention programs for high-risk youth. Journal of Primary Prevention, 25(2), 171-194. http://dx.doi.org/10.1023/B:JOPP.0000042388.63695.3f

Steinhausen, H., Eschmann, S., \& Metzke, C. W. (2008). Continuity, psychosocial correlates, and outcome of problematic substance use from adolescence to young adulthood in a community sample. Child and Adolescent Psychiatry and Mental Health, 3, 37-37. http://dx.doi.org/10.1186/1753-2000-3-37

Sussman, S., Dent, C. W., \& Leu, L. (2001). The one-year prospective prediction of substance abuse and dependence among high-risk adolescents. Journal of Substance Abuse, 12(4), 373-386. http://dx.doi.org/10.1016/S0899-3289(01)00053-0

Tangney, J. P., Baumeister, R. F., \& Boone, A. L. (2004). High self - control predicts good adjustment, less pathology, better grades, and interpersonal success. Journal of personality, 72(2), 271-324. http://dx.doi.org/10.1111/j.0022-3506.2004.00263.x

Tavousi, M., Heidarnia, A., Montazeri, A., Taremian, F., Akbari, H., \& Haeri, A. (2009). Distinction between two control constructs: an application of the theory of planned behavior for substance abuse avoidance in adolescents. Ofogh-e-Danesh, 15(4), 36-44.

Tucker, J. S., Ellickson, P. L., \& Klein, D. J. (2003). Predictors of the transition to regular smoking during adolescence and young adulthood. Journal of Adolescent Health, 32(4), 314-324. http://dx.doi.org/10.1016/S1054-139X(02)00709-7

Umeh, K., \& Patel, R. (2004). Theory of planned behaviour and ecstasy use: An analysis of moderator $\begin{array}{llll}\text { interactions. British journal of health psychology, } 9(1), & \text { 25-38. }\end{array}$ http://dx.doi.org/10.1348/135910704322778704

Weintraub Austin, E., \& Chen, Y. J. (2003). the relationship of parental reinforcement of media messages to college students' alcohol-related behaviors. Journal of Health Communication, 8(2), 157-169. http://dx.doi.org/10.1080/10810730305688

Yeramaneni, S. (2010). Social Cognitive Theory Based Predictors of Alcohol Use and Binge Drinking among Asian Indian College Students in Mid-Western Universities (Doctoral dissertation, University of Cincinnati). 


\section{Copyrights}

Copyright for this article is retained by the author(s), with first publication rights granted to the journal.

This is an open-access article distributed under the terms and conditions of the Creative Commons Attribution license (http://creativecommons.org/licenses/by/3.0/). 